\title{
Estresse no cotidiano acadêmico: um estudo com pós-graduandos em Odontologia
}

\author{
Juliana Aparecida de Souza*; Cristina Berger Fadel**; Marcelo Ubiali Ferracioli****
}

\section{RESUMO}

No universo acadêmico a condição estresse vem sendo caracterizada como fato psicossocial com repercussão biológica, que ocorre quando há a percepção de ameaça real ou imaginária, avaliada como capaz de alterar o estado de conforto subjetivo provocando sensações de mal-estar transitório ou persistente. $\mathrm{O}$ objetivo desta pesquisa quantiqualitativa foi investigar a presença e o perfil do estresse entre pós-graduandos, considerando-se o período do curso vivenciado, bem como apreender os valores instituídos pelos sujeitos frente a esta perspectiva. O público-alvo foi a totalidade de acadêmicos ingressantes e concluintes de pós-graduação em Odontologia $(n=39)$, considerando-se concomitantemente mestrandos e doutorandos. A coleta de dados foi realizada através do Inventário de Sintomas de Stress para Adultos de Lipp e da técnica em entrevista Grupo Focal. Os resultados expuseram a condição estresse presente em 59,1\% dos pósgraduandos ingressantes, e em $41,2 \%$ dos concluintes. Entretanto, a associação entre estresse e momento vivenciado no curso não apresentou significância estatística. Em ambos os grupos houve predomínio da fase intitulada resistência e tendência ao desenvolvimento de sintomas psicológicos. As compreensões dos acadêmicos a respeito da etiologia do estresse revelaram concepções relacionadas ao projeto pedagógico, atuação docente e à incerteza sobre a contribuição do curso; assim como expuseram alguns desdobramentos físicos e psicológicos. Conclui-se que o fenômeno estresse esteve consideravelmente presente no ambiente da pós-graduação investigado e sugere-se o uso das percepções apreendidas como subsídio para a reformulação de práticas pedagógicas e o repensar da atuação docente, de forma a implementar ações que visem a melhoria da qualidade de vida e do desenvolvimento acadêmico.

Descritores: Educação de Pós-Graduação em Odontologia. Estresse Psicológico. Suscetibilidade a Doenças.

\section{INTRODUÇÃO}

A vida moderna traz consigo inúmeras vantagens, bem como elementos capazes de influenciar negativamente a percepção e o desempenho de papéis sociais. Dentre eles encontra-se o estresse, considerado fenômeno de alta prevalência social e cujos desdobramentos vêm alcançando campos distintos.

No universo acadêmico a condição 
estresse vem sendo caracterizada como fato psicossocial com repercussão biológica, que ocorre quando há a percepção de ameaça real ou imaginária, avaliada como capaz de alterar o estado de conforto subjetivo provocando sensações de mal-estar transitório ou persistente ${ }^{1}$.

Contudo, o estresse não é um evento que descreve apenas situações adversas e causadoras de adoecimento, ao contrário, na maior parte das vezes constitui-se processo de aprimoramento circunstancial das capacidades físico-psicológicas do sujeito para a superação da situação estressora² .

Para o diagnóstico e mensuração do estresse o instrumento nominado Inventário de Stress para Adultos de Lipp ${ }^{3}$ vem sendo amplamente utilizado, uma vez que se mostra capaz de identificar o fenômeno, caracterizar e qualificar a sua evoluçãoo ${ }^{3,4}$.

Os pós-graduandos, de uma forma geral, estão expostos a numerosos agentes estressores inerentes à sua formação continuada; dentre eles destacam-se a sobrecarga de atividades curriculares, o que leva à falta de tempo, tanto para estudo como para a vida particular e níveis elevados de exigência e atuação. Desta forma, o estresse prejudica o desempenho do estudante e pode levar ao desestímulo em relação à carreira acadêmica ${ }^{1,5}$.

No âmbito político, entretanto, o Plano Nacional de Pós-Graduação ${ }^{6}$ aponta, como estratégias para melhoria do desempenho do sistema de pós-graduação aspectos atrelados ao sistema de avaliação, as assimetrias na distribuição da pós-graduação no território nacional, a internacionalização e ao financiamento, entre outras características técnicas; em detrimento as dimensões de cuidado e humanização do sistema de ensino ${ }^{6}$.

Frente à escassez de estudos que se dediquem à elucidação do estresse entre estudantes de pós-graduação no Brasil $^{1}$, a preocupação com a qualidade de vida de populações acadêmicas e a importância da revelação precoce de alterações e fontes que causem prejuízo à saúde, com vistas à intervenção, faz-se pertinente $\mathrm{o}$ presente estudo. $\mathrm{O}$ objetivo foi investigar a presença e o perfil do estresse entre pós-graduandos de Odontologia, considerando-se início e final de curso, e apreender as suas percepções sobre fatores determinantes e desdobramentos no contexto da vida diária.

\section{MATERIAL E MÉTODO}

Esta pesquisa quanti-qualitativa, de caráter exploratório e descritivo foi aprovada pelo Comitê de Ética em Pesquisas com seres humanos de uma universidade pública brasileira (parecer $\mathrm{n}^{\circ} 266.115 / 2013$ ), respeitando os ditames da resolução 466/12 do Conselho Nacional de Saúde.

$\mathrm{O}$ estudo foi desenvolvido junto à totalidade de acadêmicos iniciantes $(n=22)$ e concluintes $(\mathrm{n}=17)$ de um programa de pósgraduação em Odontologia da região sul do Brasil, nível mestrado e doutorado. $\mathrm{O}$ ano base para a consulta foi 2014 , sendo que a coleta de dados ocorreu em dois momentos distintos: na primeira semana de atividades, para os ingressantes, e vinte e quatro horas antes do exame de qualificação para os concluintes.

Os dados quantitativos foram coletados por pesquisador treinado, por meio da utilização de um questionário sóciodemográfico simples e um instrumento, com validação científica nacional, nominado 'Inventário de Sintomas de Stress para Adultos de Lipp'- ISSL ${ }^{3}$. A tabulação dessas informações seguiu o proposto por Lipp (2000), o qual se baseia em um modelo quadrifásico (alerta, resistência, quaseexaustão e exaustão) e propõe um método de avaliação do estresse que enfatiza a Revista da ABENO • 16 (1): 50-60, 2016. 
sintomatologia somática e psicológica etiologicamente a ele ligada. Realizou-se análise descritiva das informações mediante distribuições de frequência, com emprego do teste qui-quadrado para verificar a presença de associações.

Para a apreensão das informações de caráter qualitativo empregou-se a técnica em entrevista do Grupo Focal, estruturada, inicialmente proposta por Merton et al. (1956). Esta é uma modalidade científica da pesquisa qualitativa utilizada no entendimento das diferentes percepções e atitudes acerca de um fato, prática, produto ou serviço ${ }^{8}$. A essência do grupo focal consiste na interação entre os participantes e o pesquisador, que objetiva colher dados a partir da discussão focada em tópicos específicos e diretivos ${ }^{8}$.

Foram convidados para integrar a etapa qualitativa os pós-graduandos, ingressantes e concluintes, que apresentaram níveis significativos de comprometimento com relação ao estresse $(n=9)$. Houve recusa por parte de dois sujeitos. Utilizou-se questões norteadoras construídas a partir de narrativas de sujeitos ligados ao objeto em tela e de pesquisa literária, visando abordar a percepção acadêmica sobre agentes etiológicos do estresse e suas implicações na vida diária. Os sujeitos falaram livremente sobre fatores desencadeantes de desajustes ou desarmonia no seu cotidiano pessoal e acadêmico, sobre sentimentos em relação a esses desajustes, sobre estratégias utilizadas para enfrentar as situações desarmônicas e sobre recursos para uma melhor qualidade de vida no campo da pós-graduação.

A entrevista foi realizada em espaço neutro, externo às dependências institucionais, visando a liberdade de expressão dos informantes. Esta fase teve duração de setenta minutos e foi gravada, para que não se perdesse nenhuma informação, bem como para se obter, juntamente com as palavras, a emoção ou sentimento passado pelo entrevistado. Os resultados foram transcritos, analisados manualmente e categorizados por meio da técnica da Análise de Conteúdo Temática ${ }^{9}$ e discutidos com suporte de literatura científica ${ }^{6}$. Houve realização de estudo piloto com cinco pósgraduandos de períodos distintos aos de interesse do estudo.

Os sujeitos foram previamente informados sobre os objetivos da pesquisa, seu caráter de voluntariedade e de não identificação, assim como sobre a forma de coleta, análise e destino dos dados. Os que aquiesceram com sua participação, o fizeram, inicialmente mediante o preenchimento de um Termo de Consentimento Livre e Esclarecido e de sua participação na fase quantitativa de coleta de informações.

\section{RESULTADOS E DISCUSSÃO}

A totalidade de pós-graduandos participou da etapa quantitativa $(n=39)$. A mediana de idade encontrada foi de 26 anos, com extremos em 22 e 60 anos e prevalência do sexo feminino $(81,6 \%)$. Os dados sociodemográficos foram semelhantes aos encontrados em estudo análogo, realizado por Faro (2013) ${ }^{1}$.

\section{No campo quantitativo}

A condição estresse mostrou-se presente em $59,1 \%$ dos pós-graduandos ingressantes, e em 41,2\% dos concluintes, índice que supera os resultados divulgados em pesquisas no Brasil sobre o índice de estresse na pós-graduação ${ }^{7}$, o qual gira em torno de $35 \%$. No entanto, Santos e Alves Junior $(2007)^{2}$ encontraram um índice de $40,7 \%$ entre pós-graduandos brasileiros e Pfeifer, Kranz e Scoggin $(2008)^{12}$, índice de 66,4\% em pós-graduandos americanos. 
Igualmente para ingressantes $\mathrm{e}$ concluintes, houve predomínio da fase intitulada resistência (tabela 1) e sintomatologia psicológica (tabela 2). Os pósgraduandos do sexo feminino apresentaram maior vulnerabilidade ao estresse, expondo concordância com dados encontrados em pesquisas internacionais ${ }^{13,14} \mathrm{e}$ nacionais ${ }^{1,4,11,15}$. No entanto, essa questão não se constituiu objeto do presente estudo.

A associação entre a condição estresse e o momento vivenciado pelos pósgraduandos em sua experiência de formação continuada não apresentou significância estatística $(p=0,276)$, estando este mesmo resultado presente na literatura pesquisada ${ }^{1}$

No entanto, como anteriormente citado, os pós-graduandos ingressantes expuseram índices mais elevados desse fenômeno, quando comparados aos concluintes, fato que pode ser explicado pelo processo adaptativo sofrido por esses estudantes. Esse resultado não corrobora outros achados da literatura. Autores constataram que a proximidade do final do curso implica em um incremento nos níveis de estresse, motivado pelas exigências no que tange à conclusão dos relatórios finais aliada a própria tensão da defesa, além das expectativas acerca da carreira profissional após o término da sua formação continuada $^{1,2,16}$.

$\mathrm{Na}$ presente pesquisa houve a predominância da fase intitulada resistência, em ambas as etapas em que o estresse foi evidenciado: 76,9\% e 85,7\% para ingressantes e concluintes, respectivamente. Este resultado corrobora com achados na literatura ${ }^{2,4,11}$. Este estágio do estresse é caracterizado por perfil transitório e caráter pré-patológico, com grande petição de energia adaptativa do organismo em prol do restabelecimento da homeostase interna perdida na fase de alerta ${ }^{11}$. Nesta fase de resistência, o organismo poderá apresentar sinais de enfraquecimento e, consequentemente, estará mais suscetível a doenças de uma forma geral; no entanto, se o agente estressor for abolido, o indivíduo poderá voltar ao estado de normalidade, sem implicações $^{3,11}$. Alterações como dores musculares, cansaço excessivo, cefaleias, falta de concentração, instabilidade emocional, depressão, isolamento social, hipertensão arterial, insônia, hipersensibilidade, entre outras, são comumente observadas nesse período ${ }^{4,15,17}$.

Tabela 1 - Distribuição da prevalência do estresse entre pós-graduandos em Odontologia, segundo o momento vivenciado e o modelo de evolução.

\begin{tabular}{|c|c|c|c|c|c|c|c|c|c|c|c|c|c|c|}
\hline & & \multicolumn{4}{|c|}{ Estresse } & \multicolumn{8}{|c|}{ Fase } & \multirow{3}{*}{$\begin{array}{c}\text { Amostra } \\
\text { Total }\end{array}$} \\
\hline & & \multicolumn{2}{|c|}{ Sem } & \multicolumn{2}{|c|}{ Com } & \multicolumn{2}{|c|}{ Alerta } & \multicolumn{2}{|c|}{ Resistência } & \multicolumn{2}{|c|}{$\begin{array}{c}\text { Quase } \\
\text { Exaustão }\end{array}$} & \multicolumn{2}{|c|}{ Exaustão } & \\
\hline & & $\mathrm{n}$ & $\%$ & $\mathrm{n}$ & $\%$ & $\mathrm{n}$ & $\%$ & $\mathrm{n}$ & $\%$ & $\mathrm{n}$ & $\%$ & $\mathrm{n}$ & $\%$ & \\
\hline Ingressantes & Mestrandos & 08 & 47,1 & 09 & 52,9 & 02 & 22,2 & 06 & 66,7 & 0 & 0 & 01 & 11,1 & 17 \\
\hline$(n=22)$ & Doutorandos & 01 & 20 & 04 & 80 & 0 & 0 & 04 & 100 & 0 & 0 & 0 & 0 & 05 \\
\hline Concluintes & Mestrandos & 08 & 57,1 & 06 & 42,5 & 0 & 0 & 06 & 100 & 0 & 0 & 0 & 0 & 14 \\
\hline$(n=17)$ & Doutorandos & 02 & 33,3 & 01 & 66,7 & 01 & 100 & 0 & 0 & 0 & 0 & 0 & 0 & 03 \\
\hline
\end{tabular}


Tabela 2 - Distribuição da prevalência do estresse entre pós-graduandos em Odontologia, segundo momento vivenciado e tipo de sintoma.

\begin{tabular}{|c|c|c|c|c|c|c|c|c|c|}
\hline & \multirow{2}{*}{\multicolumn{2}{|c|}{$\begin{array}{c}\text { Estresse } \\
\text { Com }\end{array}$}} & \multicolumn{4}{|c|}{ Sintomas } & \multirow{2}{*}{\multicolumn{2}{|c|}{$\begin{array}{c}\text { Equivalência } \\
\text { Físicos/Psicológicos }\end{array}$}} \\
\hline & & & & \multicolumn{2}{|c|}{ Físicos } & \multicolumn{2}{|c|}{ Psicológicos } & & \\
\hline & & $\mathrm{n}$ & $\%$ & $\mathrm{n}$ & $\%$ & $\mathrm{n}$ & $\%$ & $\mathrm{n}$ & $\%$ \\
\hline \multirow{2}{*}{ Ingressantes } & Mestrandos & 09 & 52,9 & 00 & 00 & 05 & 55,6 & 04 & 44,4 \\
\hline & Doutorandos & 04 & 80 & 00 & 00 & 02 & 50 & 02 & 50 \\
\hline \multirow{2}{*}{ Concluintes } & Mestrandos & 06 & 42,5 & 00 & 00 & 03 & 50 & 03 & 50 \\
\hline & Doutorandos & 01 & 66,7 & 00 & 00 & 00 & 00 & 01 & 100 \\
\hline
\end{tabular}

Em relação à natureza dos sintomas apresentados, a literatura apresenta majoritariamente estudos que apontam a prevalência de sintomas psicológicos ${ }^{1,18}$, condizente com os achados dessa pesquisa. No entanto, a pesquisa realizada por Santos e Alves Junior (2007) com mestrandos em Ciências da Saúde relatou maior grau de sintomas físicos, em detrimento aos psicológicos. A condição estresse manifestase principalmente por meio de sintomas psicológicos, sendo relativamente baixos os níveis de manifestações físicas. Contudo, a manutenção de níveis elevados de estresse psicológico pode levar a um processo de somatização ${ }^{11}$.

Ressalta-se aqui, em virtude do número reduzido de sujeitos, que o resultado da análise quantitativa deve ser considerado com parcimônia.

\section{No campo qualitativo}

As compreensões apresentadas pelos pós-graduandos sobre a presença de agentes estressantes em sua jornada de formação continuada compuseram duas grandes dimensões: fatores determinantes do estresse e desdobramentos físicos e psicológicos conexos. Com relação à determinação do estresse exposta pelos sujeitos do programa de pós-graduação avaliado, deve-se considerar que as características intrínsecas que norteiam o referido programa encontram-se em consonância com as determinações nacionais legais para a criação e o funcionamento dos cursos de pós-graduação stricto sensu ${ }^{19}$.

\section{Dos fatores determinantes do estresse}

Os entrevistados indicaram a saturação de atividades inerentes à pós-graduação, a má distribuição da carga horária do curso, a exiguidade de prazos para cumprir suas atividades acadêmicas, a insatisfação em relação à forma de avaliação do corpo docente, a pressão imputada pela bolsa de estudos, as exigências externas à sua área de concentração acadêmica e a incerteza sobre a contribuição do curso em sua vida profissional como fontes estressoras centrais.

Diversos estudos também evidenciam os aspectos organizacionais, com ênfase nas questões relativas ao calendário acadêmico e à submissão de prazos, como fatores estressógenos do ambiente de pósgraduação $^{2,11,18}$, sendo capazes de afetar o desempenho e até mesmo desestimular a carreira acadêmica ${ }^{1}$.

\section{“(...) tenho que entregar já (trabalho} acadêmico) e é isso, e a gente tem que dar conta, seja de manhã, de tarde, de noite, de madrugada pra dar conta. Então, na minha opinião, seria prazo."

"É que nem agora, no doutorado tem que 
fazer pré-qualificação, mas ninguém falou nada em pré-qualificar, daí tipo em setembro eles dizem: oh, todo mundo tem que pré-qualificar até final de setembro, ou até começo de outubro!"

"Você tem as tarefas pra fazer e o teu prazo é ontem, normalmente é assim ...".

As exigências qualitativas e quantitativas que norteiam os cursos de pósgraduação, na maioria das vezes, desdobramse em um nível mais elevado de julgamento por parte do corpo docente ${ }^{2,19}$, e acabam se tornando uma fonte estressora adicional para os acadêmicos ${ }^{1,11}$. Adicionando a esse fato a possibilidade de não atingir o desempenho esperado pela banca julgadora no momento da defesa, ocorre ainda uma ampliação da situação geradora de estresse ${ }^{1,2}$.

"Eu penso assim, que por ser pósgraduação nós vamos ser julgados de forma diferente, né? Então assim, a gente tem que saber que a nossa resposta tem que ser em um nível..., que você não pode chegar com uma coisa mediana, vamos supor assim: o que seria ou é aceitável para um acadêmico da graduação, para nós já é visto com outros olhos."

"Você vai passar pelo crivo, e ali eles vão te julgar e dizer se você está apto ou não está apto. Pode ouvir: vai lá e refaz tudo, né? Mas faz parte, tem que passar...".

A saturação de demandas acadêmicas durante a vivência da pós-graduação pode surgir como outro grande fator estressor entre pós-graduandos ${ }^{1,11,14,18,20}$. Essa determinação etiológica do estresse pode também desdobrar-se em sensação de cansaço devido à falta de tempo para o lazer ${ }^{14}$, sendo capaz de afetar a qualidade dos relacionamentos interpessoais externos e internos ao universo acadêmico e de comprometer a articulação de ideias e a capacidade criativa individual ${ }^{22}$. $\mathrm{O}$ excesso percebido de atividades pode ainda desenvolver um sentimento de frustração e de insatisfação com o curso ${ }^{1}$.

"Você tem aula de manhã, laboratório pra cuidar, aula à tarde e de noite, clínica. Às vezes eu tinha que ficar no laboratório até 23h, meia noite... caso contrário, não conseguia caminhar com meu experimento."

"Tudo é muito obrigatório. Além das disciplinas, seminários e outros trabalhos, como os artigos, você tem que participar de todos os congressos... isso às vezes nem é importante pra você, mas tem que ir, né?"

"Seminário toda a semana, daí a gente tem que traduzir e apresentar toda a semana... daí fora que a gente não pode parar com a pesquisa, né? Daí mexe com célula, mexe com os animais, tem que fazer experimento... eu acho que é muito sobrecarregado assim."

Um dos grandes dilemas relatados pelos pós-graduandos entrevistados foi a necessidade crescente de produção bibliográfica, em especial para os bolsistas, cujas exigências acadêmicas são maiores $^{2,5,11,14,20}$. A produção bibliográfica constitui-se um dos indicadores mais importantes da qualidade não só dos programas stricto sensu, mas também do próprio pesquisador, fato que pode desdobrarse em uma competição acadêmica insalubre capaz de afetar os relacionamentos interpessoais $^{2,5,18}$. Segundo os entrevistados, essa produção exigida pelo curso torna-se prejudicada pela obrigatoriedade das demais atividades, as quais acabam absorvendo integralmente o tempo acadêmico. A carência de tempo para o desenvolvimento das 
produções bibliográficas foi também apontada por outros estudos ${ }^{1,22}$.

"Porque mesmo eles, os professores, perceberam a queda da nossa produção. Nós não tínhamos tempo para produção de artigo, simplesmente não sobrava nada, nem tempo e nem energia."

Em relação à pressão exercida pela bolsa de estudos, outro estressógeno apontado pelos discursos, diversos estudos nacionais ${ }^{1,2,5,15,22,25}$ e internacionais ${ }^{18,27}$ constataram que esse recurso financeiro é uma das causas principais no estabelecimento da condição estresse: ora pelo baixo valor atribuído e pela impossibilidade legal de buscar complementação para a renda, ora pelo risco eminente de perder o subsídio ofertado ${ }^{1}$.

“(...) não tinha nenhuma palestra de Odontologia que houvesse por aqui que não fôssemos obrigados a assistir. Porque vocês têm bolsa!"

A distribuição da carga horária e a forma de arranjo curricular foram também percebidas como fonte geradora de estresse no presente estudo. O currículo dos cursos stricto sensu, muitas vezes, é constituído por uma sobrecarga de conhecimentos que se apresentam pouco relevantes para a prática clínica, bem como para a área de domínio de cada pós-graduando ${ }^{1,2}$.

“(...) toda a carga horária é num ano só, daí tem aula de manhã, de tarde, seminário de tarde, daí no $2^{\circ}$ ano, só pesquisa. Eu acho que nós produziríamos mais e mais tranquilamente se nós não tivéssemos tanta carga horária acumulada no início do curso."

"Tem bastante conteúdo desnecessário"! E dai você tem um monte de coisa pra cumprir e o conteúdo foge muito da realidade. Mas a gente tinha que assistir aula de tudo."
A insatisfação gerada pela obrigatoriedade de atuação em áreas que nãoafins a formação de origem de cada pósgraduando pode afetar o seu aprendizado e suas habilidades ${ }^{14,18}$. Acadêmicos que atuam em suas áreas de domínio tentem a apresentar menores níveis de estresse, pela melhor adaptação à função ou pelo enfrentamento mais eficaz durante a sua jornada da formação ${ }^{1}$.

"Então o pessoal da perio tinha que fazer matéria de dentística e daí tinha que fazer da perio, isso sobrecarregava (...) porque no mestrado eu fazia dentística, minha área, né?! No máximo prótese e agora a gente tem que fazer endo, tem que fazer perio, inclusive assim, coisas que eu não gosto."

“(...) eu entendo que eles querem fazer a gente enxergar o paciente como um todo. É o perfil, a nova filosofia, né? Quer dizer, não tão nova assim, mas é o que eles tão querendo implantar. Você enxergar o paciente como um todo. Eu acho perfeito isso, então traça um plano de tratamento e tal, mas isso não impede de, por exemplo, o mesmo paciente que tem inúmeras coisas pra fazer, então vamo fazer uma sequência lógica. Ele entra com um aluno da perio, faz uma adequação e daí ele manda pra dentística, e ai ele manda pra prótese e finaliza o caso, entendeu?"

Por fim, a incerteza em relação à contribuição do curso para a inserção profissional foi exposta pelos entrevistados. Sentimentos análogos corroboram outros achados da literatura ${ }^{1,2,18,11,23,25}$.

"Eu pensei em desistir, tentar concurso público, mas agora... (...) Eu não tinha certeza de ir pra área acadêmica, porque eu gosto bastante da clínica também, então, às vezes, eu pensava: será que todo 
esse estresse, tem que passar no mestrado, doutorado, tipo que você tem que fazer as coisas pra mostrar pra alguém, pra ser reconhecida, depois você faz um concurso, a pessoa não te conhece, às vezes entra por mérito numérico, dai será que realmente vale a pena passar por todas essas fases? Ou é melhor abrir um consultório e trabalhar ali, ou fazer um concurso público em uma prefeitura?"

\section{Dos desdobramentos físicos e psicológicos do estresse}

Esta segunda dimensão englobou eminentemente os impactos psicológicos e físicos ocasionados pela condição estresse que recaem sobre o universo da pós-graduação.

Ansiedade, nervosismo, angústia, tensão, esgotamento, falta de concentração (perda de raciocínio rápido), alteração de humor (paciência reduzida, irritabilidade, brigas) e isolamento foram os impactos psicológicos da condição estresse apontados pelos pós-graduandos. Achados similares foram relatados por outros autores ${ }^{16,18,19}$.

A ansiedade foi o sintoma manifestado pela totalidade de pós-graduandos invéstigados. Esse resultado corrobora os achados de Duque, Brondini e Luna $(2005)^{18}$, em estudo realizado com pós-graduandos em Medicina Veterinária de uma universidade do Estado de São Paulo e pode ser explicado, por exemplo, pela necessidade do acadêmico em conciliar resoluções quanto ao atendimento à comunidade e ao desenvolvimento do seu perfil de docente e pesquisador ${ }^{11}$.

Além disso, as inúmeras tarefas delegadas aos pós-graduandos, sua grande responsabilidade em corresponder a expectativas familiares e docentes, a incerteza de ingressar no mercado laboral $\mathrm{e}$ as obrigações familiares trazem como consequência a ansiedade ${ }^{18}$.

A diminuição da capacidade de raciocínio rápido, ou seja, a falta de concentração origina-se do grande esforço requerido pelo organismo na busca pelo reequilíbrio ${ }^{11,14}$ e contribui para a perda de disposição para o trabalho e estudo, além de facilitar mudanças de humor: paciência reduzida, irritabilidade, brigas $^{18}$.

"Eu me sinto esgotada, assim. Tem dias que eu não conseguia raciocinar, assim. Tinha dias que me faziam uma pergunta, eu tinha que, pode repetir a pergunta? ... risos ... Porque, sabe, não sei, perdia a capacidade de raciocínio rápido."

"Eu acho que eu estou perdendo a minha paciência rápido. Minha família disse que vai marcar um psicólogo pra mim, porque eu estou brigando em casa muito...risos."

Estudos sinalizam em suas pesquisas para as condutas de "tomar uma cervejinha" e "ficar sozinho" como formas perigosas de enfrentamento ao estresse, uma vez que estes comportamentos contribuem para o isolamento social, para prováveis casos de alcoolismo, tabagismo e consumo de outros tipos de substâncias lícitas e ilícitas ${ }^{11,14}$, acarretando em danos biopsicossociais para o pós-graduando ${ }^{12,26}$.

"Assim, tipo eu sempre chego em casa e vou direto pro quarto. (...) eu não converso com ninguém só pra terminar de escrever, entende? Dai acho que isso ajudou um pouco no estresse, né?!"

Alterações alimentares como a perda de peso, falta ou aumento de apetite, o ato de comer e vomitar, distúrbios do sono e aumento da vontade de chorar foram os impactos físicos ocasionados pelo estresse mais apontados entre os pós-graduandos pesquisados. Esses achados estão em concordância com os dados obtidos em Revista da ABENO • 16 (1): 50-60, 2016. 
pesquisas internacionais ${ }^{14.26}$.

$O$ estresse que surge devido à dinâmica da pós-graduação pode interferir na saúde dos indivíduos, gerando alterações nos hábitos de vida desses estudantes como mudanças na alimentação, no padrão do sono e na prática de atividades físicas, as quais também poderão determinar o aparecimento de novos problemas de saúde (constipação, problemas gástricos, enxaquecas e cefaleias), gerando assim necessidade de enfrentamentos adicionais ${ }^{11,14}$.

Além disso, o estresse constitui-se fator de risco para o surgimento de doenças crônicas como hipertensão, diabetes, doença arterial coronariana, e é considerado fator de predisposição para doenças mentais ${ }^{11}$. Estudos internacionais recentes associaram também a condição estresse com morte prematura $^{12-14}$.

"Eu nunca tive um tempo de sentar assim e fazer, ler como eu gostaria de ler, assim, ficava até de madrugada, de fazer os poucos e dormia menos também e dai, com isso, eu me sentia um pouco mais estressada. Eu às vezes fico sem comer, porque se eu comer, vomito."

Expõe-se como limitações inerentes a esse estudo a amostragem não probabilística, e sua pequena e setorizada amostra, fatos que induzem à necessidade do desenvolvimento de pesquisas congêneres em outros programas de pós-graduação. Portanto, recomenda-se que futuras investigações possam se dedicar à questão da representatividade populacional, ainda que acerca de regiões ou áreas do conhecimento.

Acredita-se, ainda, que estes resultados possam fomentar o interesse pela ampliação do conhecimento sobre agentes estressores e programas de pós-graduação stricto sensu, em especial sob o olhar acadêmico.

\section{CONCLUSÃO}

A partir dos resultados obtidos conclui-se que o estresse esteve consideravelmente presente entre os estudantes de pós-graduação em Odontologia. As atividades acadêmicas vivenciadas no transcorrer da pósgraduação foram consideradas como fontes geradoras de estresse, independentemente do momento do curso. Sugere-se que os resultados expostos sejam considerados em um processo de intervenção, sustentado por estratégias amplas e que englobem a adequação de práticas pedagógicas, de atividades curriculares e extracurriculares, e o repensar da atuação docente, de forma a implementar ações que visem a melhoria da qualidade de vida e do desenvolvimento acadêmico.

\section{ABSTRACT \\ Stress in the academic routine: a study with post-graduate students in Dentistry}

In the academic world the stress condition has been characterized as a psychosocial fact with biological impact, which occurs when there is a perception of real or imagined threat, assessed as able to change the subjective state of comfort causing sensations of transient or persistent malaise. The objective of this quantitative and qualitative research was to investigate the presence and profile of stress among post-graduate students, considering the period of the course, as well as to learn the values established by individuals in this perspective. The target audience was the freshman and senior academics from postgraduation in Dentistry $(n=39)$, considering concurrently masters and doctoral students. The data collection was performed using the Stress Symptoms Inventory for Adults Lipp and a technical interview focusing in theses Groups. The results showed that stress conditions were present in $59.1 \%$ of freshman post-graduate students, and $41.2 \%$ in seniors. However, the association between stress and the experienced moment in the major was not 
statistically significant $(\mathrm{p}=0,276)$. In both groups there was a predominance of a stage titled strength and tendency to develop psychological symptoms. The insights of academics regarding the etiology of stress revealed concepts related to the pedagogical project, teaching performance, and the uncertainty about the contribution of the postgraduation course; as well as they exposed some physical and psychological developments. It is concluded that the stress phenomenon was significantly present in the investigated post-graduate environment and it also recommends the use of the perceptions learned as an input for the reformulation of educational practices and also in the rethinking of teaching performance, in order to implement actions that aim improving quality of life and academic development.

Descriptors: Education Dental Graduate Psychological Stress. Susceptibility to Disease.

\section{REFERÊNCIAS}

1. Faro A. Estresse e estressores na pósgraduação: estudo com mestrandos e doutorandos no Brasil. Psic Teor Pesq. 2013;29(1):51-60.

2. Santos AF, Alves Junior A. Estresse e estratégias de enfrentamento em mestrandos de Ciências da Saúde. Psic refl crít. 2007;20(1):104-13.

3. Lipp MEN. Manual do inventário de sintomas de stress para adultos. São Paulo, SP: Casa do Psicólogo, 2000.

4. Paulino CA, Prezotto AO, Frias AC, Bataglia PR, Aprile MR. Sintomas de estresse e tontura em estudantes de pósgraduação. Rev Equil Corp Saúde. 2010;2(1):15-26.

5. Voltarelli JC. Estresse e produtividade acadêmica. Rev Med Ribeirão Preto. 2002;35(4):1-2.
6. Brasil. Ministério da Educação. Coordenação de Aperfeiçoamento de Pessoal de

7. Nível Superior Plano Nacional de PósGraduação - PNPG 2011-2020 / Coordenação de

8. Pessoal de Nível Superior. - Brasília, DF: CAPES, 2010.

9. Merton RK, Fisk M, Kendall PL. The focused interview: a manual of problems and procedures. Glencoe: Il Free Press, 1956.

10. Iervolino AS, Pelicioni MCF. A utilização do grupo focal como metodologia qualitativa na promoção da saúde. Rev Esc Enf USP.

2001;35(2):115-21.

11. Minayo MCS. O desafio do conhecimento: pesquisa qualitativa em saúde. 10 ed. São Paulo: HUCITEC, 2007. 406 p.

12. Withe A. Estresse e ansiedade. São Paulo: Vitória Régia, 2000.

13. Malagris LEN, Suassuna ATR, Bezerra DV, Hirata HP, Monteiro JLF, Silva LR et al. Níveis de estresse e características sociobiográficas de alunos de pósgraduação. Psic em Rev. 2009;15:184203.

14. Pfeifer TA, Kranz PL, Scoggin AE. Perceived stress in occupational therapy students. Occup Ther Int. 2008;15(4):221-31.

15. Kajantie E. Physiological stress response, estrogen, and the male-female mortality gap. Curr Dir Psychol. 2008;17:348-352.

16. Sharma B, Prasad S, Pandey R, Singh J, Sodhi KS, Wadhwa D. Evaluation of stress among post-graduate medical and dental students: A pilot study. Delhi Psychiatry J. 2013;16(2):312-6. 
17. Lipp MEN, Tanganelli MS. Stress e qualidade de vida em magistrados da justiça do trabalho: Diferenças entre homens e mulheres. Psic Refl Crít. 2002;15(3):537-48.

18. Louzada RCR, Silva Filho JFS. Formação do pesquisador e sofrimento mental: um estudo de caso. Psic Est. 2005;10(3):451-61.

19. Lipp MEN. O modelo quadrifásico do stress. In: Lipp MEN (Ed.) Mecanismos neuropsicofisiológicos do stress: teoria e aplicações clínicas. São Paulo, SP: Casa do Psicólogo, p. 17-21, 2003.

20. Duque JC, Brondani JT, Luna SPL. Estresse e pós-graduação em Medicina Veterinária, RBPG. 2005;2(3):134-48.

21. Brasil, Resolução CNE/CES n ${ }^{\circ} 1$, de 3 de abril de 2001. Estabelece as normas para funcionamento de cursos de pósgraduação. Diário Oficial da União, 09 abr. 2001, Seção 1, p. 12.

22. André M. Desafios da pós-graduação e da pesquisa sobre formação de professores. Educ Ling. 2007;10(15):43-59.

23. Altoé SML, Fragalli AC, Espejo MMSB. A "dor do crescimento": um estudo sobre o nível de estresse em pós-graduandos de contabilidade. GUAL. 2014;7(1): 213-33.
24. Zanella AV. Atividade criadora, produção de conhecimentos e formação de pesquisadores: Algumas reflexões. Psicol Socied. 2004;16:135-45.

25. Moreira AF. Cultura da performatividade e a avaliação da pós-graduação em educação no Brasil. Educ Rev. 2009;25(3):23-42.

26. Hyun J, Quinn B, Madon T, Lustig S. Mental health eed, awareness, and use of counseling services among international graduate students. J Am Coll Health. 2007; 56(2):109-18.

27. Louzada RCR, Silva Filho JFS. Pósgraduação e trabalho: um estudo sobre projetos e expectativas de doutorandos brasileiros. Hist Ciênc Saúde. 2005;12(2):265-82.

28. Al-Dubai SAR, Alshagga MA, Rampal KG, Sulaiman NA. Factor structure and reliability of the malay version of the perceived stress scale among malaysian medical students. Malays J Med Sci. 2012;19(3):43-9.

Correspondência para:

Cristina Berger Fadel

e-mail: cbfadel@gmail.com

Avenida Gen. Carlos Cavalcanti, 4748

84030-900 - Ponta Grossa/PR 